\title{
Decreased bone turnover in HIV-infected children on antiretroviral therapy
}

\author{
Stephanie Shiau ${ }^{1,2,3} \cdot$ Michael T. Yin $^{4} \cdot$ Renate Strehlau $^{3} \cdot$ Faeezah Patel $^{3} \cdot$ Ndileka Mbete $^{3} \cdot$ Louise Kuhn $^{1,2,3}$. \\ Ashraf Coovadia $^{3}$. Stephen M. Arpadi ${ }^{1,2,3,5}$
}

Received: 17 January 2018 / Accepted: 25 March 2018 / Published online: 5 April 2018

(C) The Author(s) 2018

\begin{abstract}
Summary In this study, we evaluated the relationships between immune activation, bone turnover, and bone mass in virally suppressed HIV-infected children and HIV-uninfected children in South Africa. We found that decreased bone mass may occur or persist independent of immune activation and altered bone turnover.

Purpose HIV-infected children and adolescents have deficits in skeletal growth which include decreases in bone mass and alterations in bone microarchitecture. However, the mechanism by which HIV infection compromises bone accrual in children and adolescents is unclear. The goal of this study was to evaluate the relationships between immune activation, bone turnover, and bone mass in a group of pre-pubertal HIV-infected children randomized to remain on ritonavir-boosted lopinavir (LPV/r)based antiretroviral therapy (ART) or switch to efavirenz-based ART in South Africa virally suppressed at the time of this study. Methods This cross-sectional analysis included 219 HIV-infected and 180 HIV-uninfected children enrolled in the CHANGES Bone Study conducted in Johannesburg, South Africa. Whole body (WB) bone mineral content (BMC) was assessed by dual xray absorptiometry and WB BMC Z-scores adjusted for sex, age, and height were generated. Bone turnover markers, including C-telopeptide of type 1 collagen (CTx) and procollagen type I N-terminal propeptide (P1NP), were analyzed. Markers of immune activation were also measured, including cytokines IL-6 and TNF-alpha, as well as soluble CD14 and high-sensitivity C-reactive protein (CRP).

Results Compared to uninfected controls, HIV-infected children had lower WB BMC Z-scores, similar IL-6 and TNF-alpha, higher soluble CD14 and high-sensitivity CRP, and lower markers of bone resorption (CTX) and bone formation (P1NP). Bone turnover markers were not different in those remaining on LPV/r or switched to efavirenz.

Conclusions Our findings suggest that in HIV-infected children with viral suppression, decreased bone accrual may occur or persist independent of immune activation and altered bone turnover.
\end{abstract}

Keywords Bone turnover markers $\cdot$ Pediatrics $\cdot$ HIV $\cdot$ Antiretroviral therapy $\cdot$ Immune activation

Stephen M. Arpadi

sma2@columbia.edu

1 Gertrude H. Sergievsky Center, College of Physicians and Surgeons, Columbia University, 630 W. 168th Street, PH 19-114, New York, NY 10032, USA

2 Department of Epidemiology, Mailman School of Public Health, Columbia University, New York, NY, USA

3 Empilweni Services and Research Unit, Rahima Moosa Mother and Child Hospital, Department of Pediatrics and Child Health, Faculty of Health Sciences, University of the Witwatersrand,

Johannesburg, South Africa

4 Department of Medicine, College of Physicians and Surgeons, Columbia University, New York, NY, USA

5 Department of Pediatrics, College of Physicians and Surgeons, Columbia University, New York, NY, USA

\section{Introduction}

HIV-infected children and adolescents have deficits in skeletal growth which include decreases in bone mass accrual and alterations in bone microarchitecture $[1,2]$. We previously reported lower bone mineral content (BMC) in a group of South African HIV-infected children who initiated antiretroviral therapy (ART) early in life before 2-3 years of age and have had excellent virologic control [3]. In particular, among children remaining on ritonavir-boosted lopinavir (LPV/r)based ART, we observe lower accrued bone mass compared to children switching to efavirenz-based ART. This disruption of bone accrual during critical periods of skeletal development can compromise adult peak bone mass and increase the risk of later life osteoporosis and fracture $[4,5]$. 
However, the mechanisms by which HIV infection compromises bone accrual in children and adolescents are not well defined. One hypothesized mechanism is that chronic immune activation associated with HIV infection, despite the use of ART, induces alterations in bone remodeling, i.e., increased bone resorption, decreased bone formation, or both, resulting in decreased bone acquisition during growth. In HIV-infected adults, higher serum levels of pro-resorptive cytokines and $\mathrm{T}$ cell activation markers are associated with lower bone mineral density (BMD) [6-9], suggestive of immune activationmediated increased bone resorption. Due to the invasive nature of bone biopsy for performing histomorphometry, insights about mechanism are largely reliant on biochemical markers of bone turnover. In the few available studies of bone turnover markers in HIV-infected children, findings are inconsistent [10-12].

The primary goal of this study was to evaluate the relationships between immune activation, bone turnover, and bone mass in a group of well-suppressed pre-pubertal HIVinfected children in urban South Africa randomized to remain on LPV/r-based ART or switch to efavirenz-based ART [13, 14]. A better mechanistic understanding may assist development of effective interventions to optimize bone health during childhood.

\section{Methods}

\section{Study population}

Of 219 HIV-infected and 219 HIV-uninfected children enrolled in the CHANGES Bone Study conducted at Rahima Moosa Mother and Child Hospital in Johannesburg, South Africa [3], all 219 HIV-infected children and 180 (82.2\%) of the HIV-uninfected children with available relevant measurements are included in this cross-sectional analysis of bone turnover and immune activation. The 219 HIV-infected children were previous participants in a non-inferiority randomized clinical trial evaluating the safety and efficacy of preemptive switching to efavirenz compared with remaining on LPV/ r $[13,14]$.

\section{Measurements and procedures}

At the study visit, demographic data were collected and all participants underwent physical examinations to obtain anthropometric measures and to assess pubertal development. For HIV-infected children, plasma HIV-RNA levels (lower limit of detection 40 copies $/ \mathrm{mL}$ ) were measured by the Abbott RealTime HIV-1 Assay (Abbott Park, Illinois, USA). CD4 counts and percentage were measured by the TruCount Method (BD Biosciences, Germany).
Additional plasma was stored at $-80^{\circ} \mathrm{C}$ and shipped to the Biomarkers Core Laboratory, Irving Institute for Clinical and Translational Research, at Columbia University Medical Center in New York, NY, USA, where they were analyzed for bone turnover markers, including C-telopeptide of type 1 collagen (CTx) (ELISA; Immunodiagnostic Systems, Scottsdale, AZ, USA) and procollagen type I N-terminal propeptide (P1NP) (RIA; Immunodiagnostic Systems, Scottsdale, AZ). Markers of immune activation were also analyzed, including pro-inflammatory, pro-resorptive cytokines interleukin-6 (IL-6) (ELISA; R\&D Systems, Minneapolis, MN) and TNF-alpha (ELISA; R\&D Systems, Minneapolis, MN, USA), as well as soluble CD14 (ELISA; R\&D Systems, Minneapolis, MN, USA), a marker of monocyte activation, and high-sensitivity C-reactive protein (CRP) (Cobas Integra 400 Plus; Roche Diagnostics, Indianapolis, IN, USA), an acute phase reactant and marker of general inflammation. In addition, plasma was analyzed for intact parathyroid hormone (iPTH) (RIA; Scantibodies Laboratory, Santee, CA, USA), serum 25-hydroxyvitamin D3 $\left(25(\mathrm{OH}) \mathrm{D}_{3}\right)$ (LCMS; Agilent, Santa Clara, CA, USA), creatinine (Cobas Integra 400 Plus; Roche Diagnostics, Indianapolis, IN), and cystatin C (Cobas Integra 400 Plus; Roche Diagnostics, Indianapolis, IN, USA). Given limited reference values on markers of immune activation, renal function, and bone turnover for children, reference ranges provided by the Biomarkers Core Laboratory were utilized.

Whole body (WB) and lumbar spine (LS) dual x-ray absorptiometry (DXA) scans were obtained using a single Hologic scanner and data was transferred to the Image Reading Center in New York for reading. WB and LS BMC Z-scores adjusted for sex, age, and height based on reference normative values from the United States Bone Mineral Density in Childhood Study were generated [15], as there are no South African or African reference ranges available. To account for potential effects of growth velocity on bone turnover markers, we assessed growth velocity (cm/year) for HIV-infected children by calculating the change in height over time between the date of DXA scan and the previous study visit [16].

Signed informed consent was provided by each child's parent or guardian; children provided assent if they were at least 7 years old and deemed able to understand. The study was approved by the Institutional Review Boards of Columbia University (New York, NY, USA) and the University of the Witwatersrand (Johannesburg, South Africa).

\section{Statistical analysis}

Chi-squared or Fisher's exact tests were used to compare proportions, $t$ tests to compare means, and Wilcoxon rank-sum test to compare medians. Linear regression was first used to evaluate the association between HIV and bone turnover markers, adjusted for age, sex, $25(\mathrm{OH}) \mathrm{D}_{3}$, and $\mathrm{WB}$ bone area. Given potential differences in the number of osteoblasts 
between groups, we included WB bone area as a proxy to account for this in the association between HIV and bone turnover markers, assuming the groups had no difference in the number of osteoblasts per surface area [17]. Next, linear regression was used to evaluate the association between bone turnover markers and $\mathrm{WB}$ BMC and LS BMC $Z$-scores and between markers of immune activation and bone turnover markers, adjusted for age and sex. Linear regression analyses were also conducted among HIV-infected children evaluating the associations between treatment regimen and bone turnover markers, adjusted for age, sex, and $25(\mathrm{OH}) \mathrm{D}_{3}$ and, as bone turnover markers vary with growth velocity as well as bone surface area [17], growth velocity and WB bone area were also included. All $p$ values are two-tailed and $p$ values $<$ 0.05 were considered statistically significant. All statistical calculations were performed using SAS version 9.4 (Cary, North Carolina, USA).

\section{Results}

\section{Characteristics}

Characteristics of the study participants are shown in Table 1. The 219 HIV-infected children (49\% male) and 180 HIVuninfected children (55\% male) were between 5 and 9 years of age (mean 6.7 years). One hundred thirteen HIV-infected children were previously randomized to remain on LPV/r and 106 were randomized to switch to efavirenz. Children were also receiving two nucleoside reverse transcriptase inhibitors including lamivudine and either abacavir, zidovudine, or stavudine. None had any past or current use of tenofovir and none was receiving corticosteroids or antiepileptic medications. The mean (SD) duration on treatment for HIV-infected children was 5.7 (1.1) years (range 2.8-8.7) and this visit occurred 1-4 years (mean 2.1 years) after randomization in the clinical trial. At the time of evaluation, $93.6 \%$ of children had HIV-1 RNA $<400$ copies $/ \mathrm{mL}$ and a mean (SD) CD4 percentage of 37.3 (7.1).

HIV-infected children had lower mean WB BMC Z-score compared with the HIV-uninfected group ( -0.95 vs. -0.79 , $p=0.05$ ), similar to the result previously reported [3]. LS BMC $Z$-score was not different between groups $(-0.22$ vs. $-0.38, p=0.08)$. The mean concentration of $25(\mathrm{OH}) \mathrm{D}_{3}$ was higher in HIV-infected children than in HIV-uninfected children (30.6 vs. $24.3 \mathrm{ng} / \mathrm{mL}, p<0.01)$. A higher proportion of HIV-infected children had $25(\mathrm{OH}) \mathrm{D}_{3}>20 \mathrm{ng} / \mathrm{mL}$ ( 84.9 vs. $74.4 \%, p=0.009$ ). Mean iPTH concentration was similar in the groups ( 31.1 vs. $32.1 \mathrm{pg} / \mathrm{mL}, p=0.5)$. The mean cystatin $\mathrm{C}$ and creatinine levels were lower in the HIV-infected group, but overall, few HIV-infected or HIV-uninfected children had elevated cystatin $\mathrm{C}$ (Table 1). HIV-infected children randomized to remain on LPV/r had lower WB BMC and LS BMC Z- score compared to HIV-infected children randomized to switch to efavirenz. Those switched to efavirenz had a significantly lower mean $25(\mathrm{OH}) \mathrm{D}_{3}$ concentration than those remaining on LPV/r (26.9 vs. $34.0 \mathrm{ng} / \mathrm{mL}, p<0.001)$, as well as a greater proportion with $25(\mathrm{OH}) \mathrm{D}_{3}<20 \mathrm{ng} / \mathrm{mL}$ (18.6 vs. $7.2 \%, p=0.012$ ).

\section{Immune activation}

As shown in Table 2, mean IL-6 concentration was similar in HIV-infected and HIV-uninfected children; only seven children (four HIV-infected and three HIV-uninfected) had elevated IL-6. Although mean TNF-alpha was slightly lower in the HIV-infected group, results for most children fell well within the reference range provided by the Biomarkers Core Laboratory $(<4.71 \mathrm{pg} / \mathrm{mL})$. Mean soluble CD14 concentration was higher in the HIV-infected group compared to the HIV-uninfected group (1453 vs. $1195 \mathrm{ng} / \mathrm{mL}, p<0.0001$ ) and $8.3 \%$ of the HIV-infected children had an elevated soluble $\mathrm{CD} 14 \geq 2300 \mathrm{ng} / \mathrm{mL}$ compared to $2.2 \%$ of the HIV-uninfected children $(p=0.005)$. Similarly, mean high-sensitivity CRP was higher in the HIV-infected group compared to the HIVuninfected group $(4.75$ vs. $1.81 \mathrm{mg} / \mathrm{dL}, p=0.008)$ and a higher proportion of the HIV-infected children had an elevated high-sensitivity CRP concentration $\geq 0.5 \mathrm{mg} / \mathrm{dL}$ than the HIVuninfected children ( 59.4 vs. $43.3 \%, p=0.002)$.

The HIV-infected children randomized to remain on LPV/r had a non-significantly higher mean IL-6 concentration compared to those switched to efavirenz (2.17 vs. $1.25 \mathrm{pg} / \mathrm{mL}, p=$ 0.059 ); four $(1.8 \%)$ in the LPV/r group and zero $(0 \%)$ in those switched to efavirenz had concentrations exceeding the upper limit of the reference range. In addition, those on LPV/r had a higher mean TNF-alpha concentration compared to those switched to efavirenz ( $2.40 \mathrm{vs.} 1.89 \mathrm{pg} / \mathrm{mL}, p=0.005)$. Four in the LPV/r group and two in the group switched to efavirenz had TNF-alpha concentrations that exceeded the upper limit of the reference range. The mean soluble CD14 and high-sensitivity CRP concentrations were similar in the two treatment groups.

\section{Bone turnover markers}

As shown in Table 3, CTX (1.72 vs. $2.05 \mathrm{ng} / \mathrm{mL}, p<0.01)$ and P1NP (584 vs. $634 \mathrm{ng} / \mathrm{mL}, p<0.01)$ concentrations were lower in HIV-infected than in HIV-uninfected children. CTX and P1NP remained lower for the HIV-infected group after adjusting for age, sex, $25(\mathrm{OH}) \mathrm{D}_{3}$, and $\mathrm{WB}$ bone area. CTX and P1NP concentrations for most HIV-infected and HIVuninfected children fell within the reference ranges provided by the Biomarkers Core Laboratory: $93.6 \%$ of HIV-infected children and $94.4 \%$ of the HIV-uninfected children had a CTX level between 0.83 and $3.32 \mathrm{ng} / \mathrm{mL} ; 88.6 \%$ of the HIVinfected group and $86.1 \%$ of the HIV-uninfected group had a P1NP level between 19 and $830 \mathrm{ng} / \mathrm{mL}$. Among HIV- 
Table 1 Characteristics of 219 HIV-infected and 180 HIV-uninfected children in Johannesburg, South Africa

\begin{tabular}{|c|c|c|c|c|c|c|}
\hline Characteristic & $\begin{array}{l}\text { HIV+ } \\
(N=219)\end{array}$ & $\begin{array}{l}\text { HIV- } \\
(N=180)\end{array}$ & $P$ & $\begin{array}{l}\mathrm{LPV} / \mathrm{r} \\
(N=113)\end{array}$ & $\begin{array}{l}\mathrm{EFV} \\
(N=106)\end{array}$ & $P$ \\
\hline Male, $N(\%)$ & $107(48.9)$ & $99(55.0)$ & 0.22 & $53(46.9)$ & $54(50.9)$ & 0.55 \\
\hline Age, mean (SD) & $6.4(1.2)$ & $7.1(1.6)$ & $<0.001$ & $6.4(1.3)$ & $6.3(1.2)$ & 0.74 \\
\hline Tanner stage $1, N(\%)$ & $215(98.2)$ & $172(95.6)$ & 0.128 & $113(100.0)$ & $102(96.2)$ & 0.053 \\
\hline Weight in kg, mean (SD) & $19.2(3.9)$ & $22.7(5.6)$ & $<0.0001$ & $19.0(3.6)$ & $19.4(4.1)$ & 0.49 \\
\hline WAZ, mean (SD) & $-0.83(0.9)$ & $-0.32(1.1)$ & $<0.0001$ & $-0.90(0.9)$ & $-0.76(0.9)$ & 0.25 \\
\hline Underweight, $N(\%)$ & $24(11.0)$ & $6(3.3)$ & 0.004 & $15(13.3)$ & $9(8.5)$ & 0.26 \\
\hline Height in cm, mean (SD) & $110.3(8.3)$ & $117.2(9.9)$ & $<0.0001$ & $111(8.6)$ & $110(8.0)$ & 0.51 \\
\hline $\mathrm{HAZ}$, mean (SD) & $-1.40(0.9)$ & $-0.87(0.92)$ & $<0.0001$ & $-1.36(0.9)$ & $-1.45(0.9)$ & 0.48 \\
\hline Stunted $(\mathrm{HAZ}<-2), N(\%)$ & $61(27.9)$ & $18(10.0)$ & $<0.0001$ & $30(26.6)$ & $31(29.3)$ & 0.66 \\
\hline Body mass index (BMI), mean (SD) & $15.7(1.6)$ & $16.3(2.2)$ & 0.0008 & $15.4(1.4)$ & $15.9(1.7)$ & 0.018 \\
\hline BAZ, mean (SD) & $0.08(1.0)$ & $0.28(1.1)$ & 0.049 & $-0.05(0.9)$ & $0.21(1.0)$ & 0.046 \\
\hline Age at ART start in months, mean (SD) & $8.8(6.8)$ & & & $9.2(6.7)$ & $8.5(6.8)$ & 0.49 \\
\hline Plasma HIV-1 RNA < 400 copies/mL, $N(\%)$ & 205 (93.6) & & & $105(92.9)$ & $100(94.3)$ & 0.67 \\
\hline CD4 percentage, mean (SD) & $37.3(7.1)$ & & & $35.7(6.6)$ & $39.0(7.2)$ & 0.0006 \\
\hline Treatment duration in years, mean (SD) & $5.7(1.1)$ & & & $5.7(1.1)$ & $5.7(1.1)$ & 0.98 \\
\hline Time since randomization in years, mean (SD) & $2.1(0.6)$ & & & $2.2(0.6)$ & $2.1(0.6)$ & 0.54 \\
\hline Remained on randomized regimen at time of bone assessment, $N(\%)$ & $201(91.8)$ & & & $102(90.3)$ & $99(93.4)$ & 0.40 \\
\hline Whole body BMC Z-score & $-0.95(0.83)$ & $-0.79(0.78)$ & 0.05 & $-1.20(0.82)$ & $-0.68(0.76)$ & $<0.001$ \\
\hline Lumbar spine BMC Z-score & $-0.22(0.89)$ & $-0.38(0.83)$ & 0.08 & $-0.45(0.89)$ & $0.01(0.84)$ & 0.0001 \\
\hline $\begin{array}{l}25(\mathrm{OH}) \mathrm{D}_{3}(\mathrm{ng} / \mathrm{mL}) \text {, mean }(\mathrm{SD}) \\
\text { Missing }\end{array}$ & $\begin{array}{l}30.6(9.8) \\
6\end{array}$ & $24.3(6.3) 2$ & $<0.0001$ & $\begin{array}{l}34.0(10.0) \\
2\end{array}$ & $\begin{array}{l}26.9(8.1) \\
4\end{array}$ & $<0.0001$ \\
\hline $25(\mathrm{OH}) \mathrm{D}_{3}<20 \mathrm{ng} / \mathrm{mL}, N(\%)$ & $27(12.7)$ & $44(24.7)$ & 0.002 & $8(7.2)$ & $19(18.6)$ & 0.012 \\
\hline $\begin{array}{l}\text { iPTH }(\mathrm{pg} / \mathrm{mL}) \\
\text { Missing }\end{array}$ & $\begin{array}{l}31.1(12.9) \\
3\end{array}$ & $\begin{array}{l}32.1(15.7) \\
3\end{array}$ & 0.50 & $\begin{array}{l}30.7(12.1) \\
1\end{array}$ & $\begin{array}{l}31.5(13.7) \\
2\end{array}$ & 0.62 \\
\hline $\mathrm{iPTH} \geq 65 \mathrm{pg} / \mathrm{mL}, N(\%)$ & $3(1.4)$ & $7(4.0)$ & 0.11 & $2(1.8)$ & $1(1.0)$ & 0.61 \\
\hline $\begin{array}{l}\text { Cystatin C (mg/L) } \\
\text { Missing }\end{array}$ & $\begin{array}{l}0.68(0.10) \\
4\end{array}$ & $\begin{array}{l}0.72(0.10) \\
2\end{array}$ & $<0.0001$ & $\begin{array}{l}0.70(0.11) \\
1\end{array}$ & $\begin{array}{l}0.67(0.09) \\
3\end{array}$ & 0.029 \\
\hline Cystatin $\mathrm{C} \geq 0.95 \mathrm{mg} / \mathrm{L}, N(\%)$ & $5(2.3)$ & $2(1.1)$ & 0.37 & $4(3.6)$ & $1(1.0)$ & 0.21 \\
\hline Creatinine $(\mathrm{mg} / \mathrm{dL})$ & $0.38(0.07)$ & $0.44(0.08)$ & $<0.0001$ & $0.38(0.08)$ & $0.38(0.07)$ & 0.96 \\
\hline Missing & 4 & 3 & & 1 & 3 & \\
\hline Creatinine $\geq 1.20 \mathrm{mg} / \mathrm{dL}, N(\%)$ & $0(0.0)$ & $0(0.0)$ & 1.0 & $0(0.0)$ & $0(0.0)$ & 1.0 \\
\hline
\end{tabular}

$Z$-scores from Bone Mineral Density in Childhood Study (adjusted for age, sex, race, and height-for-age $Z$-score)

$B M C$ bone mineral content, $B M D$ bone mineral density, $W A Z$ weight-for-age $Z$-score, $H A Z$ height-for-age $Z$-score, $B A Z$ BMI-for-age $Z$-score, $i P T H$ intact parathyroid hormone, $L P V / r$ ritonavir-boosted lopinavir, $E F V$ efavirenz, $i P T H$ intact parathyroid hormone, $25(\mathrm{OH}) \mathrm{D}_{3}$ serum 25 -hydroxyvitamin D3

infected children, CTX and P1NP levels did not differ between children randomized to remain on LPV/r and children randomized to switch to efavirenz at a mean of 2.1 years after randomization (Table 3), nor were differences apparent after adjusting for age, sex, $25(\mathrm{OH}) \mathrm{D}_{3}$, growth velocity, and $\mathrm{WB}$ bone area. There were no associations between bone turnover markers and WB BMC and LS BMC Z-scores.

\section{Relationships between markers of immune activation and bone turnover markers in HIV-infected children}

Next, we evaluated relationships between markers of immune activation and bone turnover markers among our HIV-infected children. None of the markers of immune activation were associated with CTX. Although soluble CD14 and TNFalpha were not associated with P1NP, IL-6 was negatively associated with P1NP $(\beta=-0.87, \mathrm{SE}=0.34, p=0.01)$, even after adjustment for age and sex. Similarly, high-sensitivity CRP was negatively associated with $\mathrm{P} 1 \mathrm{NP}(\beta=-3.6, \mathrm{SE}=$ $1.2, p=0.002)$, even after adjustment for age and sex. Stratifying these relationships by treatment group (LPV/r or efavirenz) resulted in similar findings (data not shown).

\section{Discussion}

In this study of South African HIV-infected children on ART with mainly undetectable viral load on long-term effective 
Table 2 Markers of immune activation of 219 HIV-infected and 180 HIV-uninfected children in Johannesburg, South Africa

\begin{tabular}{|c|c|c|c|c|c|c|}
\hline Measurement & $\begin{array}{l}\text { HIV+ } \\
(N=219)\end{array}$ & $\begin{array}{l}\text { HIV- } \\
(N=180)\end{array}$ & $P$ & $\begin{array}{l}\mathrm{LPV} / \mathrm{r} \\
(N=113)\end{array}$ & $\begin{array}{l}\mathrm{EFV} \\
(N=106)\end{array}$ & $P$ \\
\hline IL-6 (pg/mL), mean (SD) & $1.72(3.6)$ & $1.73(3.49)$ & 0.97 & $2.17(4.8)$ & $1.25(1.4)$ & 0.059 \\
\hline Missing & 0 & 0 & & 0 & 0 & \\
\hline IL-6 $\geq 9.96 \mathrm{pg} / \mathrm{mL}, N(\%)$ & $4(1.8)$ & $3(1.7)$ & 0.66 & $4(3.5)$ & $0(0.0)$ & 0.051 \\
\hline TNF-alpha (pg/mL), mean (SD) & $2.15(1.35)$ & $2.60(1.21)$ & 0.0008 & $2.40(1.33)$ & $1.89(1.34)$ & 0.005 \\
\hline Missing & 0 & 1 & & 0 & 0 & \\
\hline TNF-alpha $\geq 4.71 \mathrm{pg} / \mathrm{mL}, N(\%)$ & $6(2.7)$ & $9(5.0)$ & 0.23 & $4(3.5)$ & $2(1.9)$ & 0.45 \\
\hline Soluble CD14 (ng/mL), mean (SD) & $1453(550)$ & $1195(437)$ & $<0.0001$ & $1428(535)$ & $1480(566)$ & 0.493 \\
\hline Missing & 1 & 0 & & 0 & 1 & \\
\hline Soluble CD14 $\geq 2300 \mathrm{ng} / \mathrm{mL}, N(\%)$ & $18(8.3)$ & $4(2.2)$ & 0.005 & $10(8.9)$ & $8(7.6)$ & 0.61 \\
\hline High-sensitivity C-reactive protein $(\mathrm{mg} / \mathrm{dL})$, mean $(\mathrm{SD})$ & $4.00(10.4)$ & $1.81(4.02)$ & 0.008 & $4.75(12.6)$ & $3.2(7.5)$ & 0.28 \\
\hline Missing & 5 & 2 & & 2 & 3 & \\
\hline High-sensitivity C-reactive protein $\geq 0.5 \mathrm{mg} / \mathrm{dL}, N(\%)$ & $127(59.4)$ & $77(43.3)$ & 0.002 & $64(56.6)$ & $64(60.4)$ & 0.57 \\
\hline
\end{tabular}

$I L-6$ interleukin-6, TNF-alpha tumor necrosis factor alpha, $L P V / r$ ritonavir-boosted lopinavir, $E F V$ efavirenz

ART, we found lower bone mass, limited evidence of immune activation, and lower measures of bone remodeling compared to HIV-uninfected children.

Though our bone turnover markers were lower in HIVinfected than in HIV-uninfected children, both groups fell within the range reported in other studies of bone turnover in children without HIV $[16,18]$. Our finding of less bone remodeling among HIV-infected children differs from results reported in older studies of HIV-infected children and adolescents $[11,12,19,20]$. These differences may be explained by varied study population characteristics with respect to level of viral suppression, duration and type of ART exposure, and differences in specific bone turnover markers assayed. We were unable to have the children fast for the blood measurement due to travel times to the study site and the age of the children. Mora et al. found that HIV-infected children and adolescents aged 6-17 years on ART, including indinavir, nelfinavir, and ritonavir-based regimens, had higher bone formation (bone alkaline phosphatase, BALP) as well as higher bone resorption (N-telopeptide, NTX) than HIV-uninfected children [11]. Similarly, Tan et al. reported higher bone formation, as measured by osteocalcin, in HIV-infected children on protease inhibitors ages 2 to 12 years, than HIV-uninfected controls [12]. In contrast to these two studies in which children were receiving a variety of older protease inhibitors (e.g., indinavir and nelfinavir) and nucleoside reverse transcriptase inhibitors (e.g., didanosine and stavudine), children in our study were initiated and suppressed early in life with currently recommended three-drug regimens. Over $90 \%$ of children in our study were virally suppressed, while only $40 \%$ of the participants in Tan et al. had HIV RNA $<400$ copies $/ \mathrm{mL}$ at the time of study.

More recently, a European study of 54 HIV-infected children and adolescents aged 6-19 years reported that HIV-

Table 3 Bone turnover markers of 219 HIV-infected and 180 HIV-uninfected children in Johannesburg, South Africa

\begin{tabular}{|c|c|c|c|c|c|c|}
\hline Measurement & $\begin{array}{l}\mathrm{HIV}+ \\
(N=219)\end{array}$ & $\begin{array}{l}\mathrm{HIV}- \\
(N=180)\end{array}$ & $P$ & $\begin{array}{l}\mathrm{LPV} / \mathrm{r} \\
(N=113)\end{array}$ & $\begin{array}{l}\mathrm{EFV} \\
(N=106)\end{array}$ & $P$ \\
\hline CTX (ng/mL), mean (SD) & $1.72(0.63)$ & $2.05(0.69)$ & $<0.0001$ & $1.70(0.63)$ & $1.75(0.64)$ & 0.53 \\
\hline CTX (ng/mL), median (IQR) & $1.67(1.22,2.10)$ & $2.05(1.55,2.55)$ & $<0.0001$ & $1.67(1.22,2.04)$ & $1.67(1.24,2.19)$ & 0.57 \\
\hline \multicolumn{7}{|l|}{ CTX (ng/mL), $N(\%)$} \\
\hline $\begin{array}{l}<0.83 \\
0.83-3.32 \text { (normal) }\end{array}$ & $\begin{array}{l}12(5.5) \\
205(93.6)\end{array}$ & $\begin{array}{l}5(2.8) \\
170(94.4)\end{array}$ & \multirow[t]{2}{*}{0.16} & $\begin{array}{l}6(5.3) \\
106(93.8)\end{array}$ & $\begin{array}{l}6(5.7) \\
99(93.4)\end{array}$ & \multirow[t]{2}{*}{0.99} \\
\hline$\geq 3.32$ & $2(0.9)$ & $5(2.8)$ & & $1(0.9)$ & $1(0.9)$ & \\
\hline P1NP (ng/mL), mean (SD) & $584(183)$ & $634(173)$ & 0.005 & $585(179)$ & $583(188)$ & 0.94 \\
\hline P1NP (ng/mL), median (IQR) & $564(454,680)$ & $616(522,719)$ & 0.002 & $560(469,686)$ & $566(454,664)$ & 0.76 \\
\hline \multicolumn{7}{|l|}{$\mathrm{P} 1 \mathrm{NP}(\mathrm{ng} / \mathrm{mL}), N(\%)$} \\
\hline $\begin{array}{l}<190 \\
190-830 \text { (normal) }\end{array}$ & $\begin{array}{l}1(0.5) \\
194(88.6)\end{array}$ & $\begin{array}{l}0(0.0) \\
155(86.1)\end{array}$ & \multirow[t]{2}{*}{0.53} & $\begin{array}{l}1(0.9) \\
100(88.5)\end{array}$ & $\begin{array}{l}0(0.0) \\
94(88.7)\end{array}$ & \multirow[t]{2}{*}{1.0} \\
\hline$\geq 830$ & $24(11.0)$ & $25(13.9)$ & & $12(10.6)$ & $12(11.3)$ & \\
\hline
\end{tabular}

$L P V / r$ ritonavir-boosted lopinavir, $E F V$ efavirenz 
infected children had higher bone formation (BALP) than controls, possibly due to lower serum concentrations of sclerostin and Dkk1, inhibitors of the Wnt/b-catenin pathway, a critical regulator of skeletal development [19]. Another study of adolescents aged 10-18 years in Thailand found increased bone turnover markers to be inversely associated with BMD Z-scores [20]. Differences in findings among publications may also be attributable to participant age and maturity, as well as variable time to ART initiation after HIV infection. For example, there was no age overlap between our study (59 years) and Sudjaritruk et al., and all but four HIV-infected children in our study were Tanner stage 1 whereas $73 \%$ of the population in Sudjaritruk et al. was Tanner stages 3-5. Of note, we observed low bone formation in a setting of no tenofovir use.

Also unexpected, we did not observe increased levels of pro-inflammatory pro-resorptive cytokines (IL-6 and TNF-alpha) in our HIV-infected group. This may be due to ART initiation early in life and well-controlled virus for an extended period of time. In addition, the HIV-infected children had higher vitamin $\mathrm{D}$ than the HIV-uninfected children which is likely due to greater proportion of children with HIV receiving multivitamin supplements; vitamin D has recently been shown to attenuate immune activation in youth with HIV [21]. Aside from a weak negative association between IL-6 and P1NP, no evidence of immune activation-mediated increased bone resorption, as seen in other studies of children and adults, was seen $[9,22]$. Also observed were increased levels of soluble CD14, a marker of monocyte activation, in our HIV-infected group. Similarly, higher levels of plasma soluble CD14 at longitudinal time points following viral load suppression and normalization of CD8+ T cell activation have been reported in a study of HIV-infected children in Vietnam [23]. In contrast to findings from a cross-sectional study of adolescents ages 14-25 years by Ruan et al., we did not observe a significant inverse correlation between soluble CD14 and our measures of bone mass [24]. Ruan et al. measured soluble CD14 and bone mass early in infection (2-3 years); although HIV-associated monocyte activation does not appear to be responsible for the decreased bone accrual we observe among HIV-infected children in our study, it may play a role closer to the time of infection or during periods of viremia. Persistent monocyte activation may be of great concern for HIV-infected children, since soluble CD14 has been proposed as an independent predictor of mortality as well as subsequent non-AIDS events (e.g., cardiovascular disease) in adults with HIV $[25,26]$. Of note, high-sensitivity CRP levels were elevated in $59.4 \%$ of the HIV-infected children and $43.3 \%$ of the HIV-uninfected children, possibly reflecting elevated levels of general inflammation in this setting.

Although we saw differences in bone mass between children remaining on LPV/r and children switched to efavirenz, bone turnover markers did not discriminate between the groups, and both treatment groups (i.e., LPV/r and efavirenz) had lower bone turnover markers compared to HIV-uninfected children. The null finding did not appear to be explained by growth velocity. As expected, we observed lower vitamin D levels in the children switched to efavirenz. Efavirenz has been implicated in induction of 24-hydroxylase (CYP24A1), a cytochrome P450 enzyme that degrades $25(\mathrm{OH}) \mathrm{D}$ and $1,25(\mathrm{OH})_{2} \mathrm{D}$ into an inactive form [27]. The significance of this to bone metabolism is unclear given that iPTH concentrations were not elevated among those switched to efavirenz nor did they have lower BMC. Among the 19 HIV-infected children in the efavirenz group with low vitamin $\mathrm{D}\left(25(\mathrm{OH}) \mathrm{D}_{3}<\right.$ $20 \mathrm{ng} / \mathrm{mL}$ ), iPTH ranged from 13 to $107 \mathrm{pg} / \mathrm{mL}$, with a mean of $36.0 \mathrm{pg} / \mathrm{mL}$, and few above $65 \mathrm{pg} / \mathrm{mL}$.

Children remaining on LPV/r had higher levels of pro-inflammatory, pro-resorptive cytokines IL-6 and TNF-alpha compared to children switched to efavirenz. This may be a direct effect of lopinavir and ritonavir, which in ex vivo studies in macrophages induce IL- 6 and TNF-alpha expression via ERK signaling pathways and unfolded protein response [28]. Nonetheless, the relationship between markers of immune activation and bone turnover markers was not different between children on LPV/r and children on efavirenz. Furthermore, no relationship between the bone turnover markers and bone were identified. It is possible that the differences in bone mass between the treatment groups could have been related to differences in bone turnover that occurred close to the time of randomization that are no longer detectable. Future studies closer to the time of treatment switch may help clarify this.

ART initiation studies in adults suggest that the greatest declines in BMD occur around the time of ART initiation, likely due to a combination of direct ART effect and immune activation-mediated bone resorption [29, 30]. Our findings suggest that in HIV-infected children with viral suppression on stable ART, decreases in BMD persist independent of immune activation and altered bone turnover. This study takes place well beyond the time of initial viral suppression and is limited by a single measurement of bone turnover markers and markers of immune activation, which vary throughout childhood lack established reference ranges [18, 31]. Longitudinal studies that include serial measures of immune activation, bone turnover, and BMD are necessary to fully appreciate the dynamics of immune activation and bone modeling and remodeling in growing children with HIV.

Funding information This study received financial support from the National Institute of Child Health and Human Development (HD 073977, HD 073952).

\section{Compliance with ethical standards}

Signed informed consent was provided by each child's parent or guardian; children provided assent if they were at least 7 years old and deemed able to understand. The study was approved by the Institutional Review 
Boards of Columbia University (New York, NY, USA) and the University of the Witwatersrand (Johannesburg, South Africa).

\section{Conflicts of interest None.}

Open Access This article is distributed under the terms of the Creative Commons Attribution 4.0 International License (http:// creativecommons.org/licenses/by/4.0/), which permits unrestricted use, distribution, and reproduction in any medium, provided you give appropriate credit to the original author(s) and the source, provide a link to the Creative Commons license, and indicate if changes were made.

\section{References}

1. Mora S, Zamproni I, Beccio S, Bianchi R, Giacomet V, Vigano A (2004) Longitudinal changes of bone mineral density and metabolism in antiretroviral-treated human immunodeficiency virusinfected children. J Clin Endocrinol Metab 89(1):24-28

2. Jacobson DL, Lindsey JC, Gordon CM, Moye J, Hardin DS, Mulligan K, Aldrovandi GM, Pediatric AIDS Clinical Trials Group P1045 team (2010) Total body and spinal bone mineral density across Tanner stage in perinatally HIV-infected and uninfected children and youth in PACTG 1045. AIDS 24(5):687-696

3. Arpadi SM, Shiau S, Strehlau R, Patel F, Mbete N, McMahon DJ et al (2016) Efavirenz is associated with higher bone mass in South African children with HIV. AIDS 30(16):2459-2467

4. Yin MT, Lund E, Shah J, Zhang CA, Foca M, Neu N, Nishiyama KK, Zhou B, Guo XE, Nelson J, Bell DL, Shane E, Arpadi SM (2014) Lower peak bone mass and abnormal trabecular and cortical microarchitecture in young men infected with HIV early in life. AIDS 28(3):345-353

5. Shiau S, Broun EC, Arpadi SM, Yin MT (2013) Incident fractures in HIV-infected individuals: a systematic review and meta-analysis. AIDS 27(12):1949-1957

6. Manavalan JS, Arpadi S, Tharmarajah S, Shah J, Zhang CA, Foca M, Neu N, Bell DL, Nishiyama KK, Kousteni S, Yin MT (2016) Abnormal bone acquisition with early-life HIV infection: role of immune activation and senescent osteogenic precursors. J Bone Miner Res 31(11):1988-1996

7. Gazzola L, Bellistri GM, Tincati C, Ierardi V, Savoldi A, Del Sole A et al (2013) Association between peripheral T-lymphocyte activation and impaired bone mineral density in HIV-infected patients. $\mathrm{J}$ Transl Med 11:51

8. Erlandson KM, O'Riordan M, Labbato D, McComsey GA (2014) Relationships between inflammation, immune activation, and bone health among HIV-infected adults on stable antiretroviral therapy. J Acquir Immune Defic Syndr 65(3):290-298

9. Yin MT, McMahon DJ, Ferris DC, Zhang CA, Shu A, Staron R et al (2010) Low bone mass and high bone turnover in postmenopausal human immunodeficiency virus-infected women. J Clin Endocrinol Metab 95(2):620-629

10. Zamboni G, Antoniazzi F, Bertoldo F, Lauriola S, Antozzi L, Tato L (2003) Altered bone metabolism in children infected with human immunodeficiency virus. Acta Paediatr 92(1):12-16

11. Mora S, Sala N, Bricalli D, Zuin G, Chiumello G, Vigano A (2001) Bone mineral loss through increased bone turnover in HIV-infected children treated with highly active antiretroviral therapy. AIDS 15(14): 1823-1829

12. Tan BM, Nelson RP Jr, James-Yarish M, Emmanuel PJ, Schurman SJ (2001) Bone metabolism in children with human immunodeficiency virus infection receiving highly active anti-retroviral therapy including a protease inhibitor. J Pediatr 139(3):447-451
13. Coovadia A, Abrams EJ, Strehlau R, Shiau S, Pinillos F, Martens L, Patel F, Hunt G, Tsai WY, Kuhn L (2015) Efavirenz-based antiretroviral therapy among nevirapine-exposed HIV-infected children in South Africa: a randomized clinical trial. JAMA 314(1817): 1808-1817

14. Murnane PM, Strehlau R, Shiau S, Patel F, Mbete N, Hunt G, Abrams EJ, Coovadia A, Kuhn L (2017) Switching to efavirenz versus remaining on ritonavir-boosted lopinavir in HIV-infected children exposed to nevirapine: long-term outcomes of a randomized trial. Clin Infect Dis 65(3):477-485

15. Zemel BS, Kalkwarf HJ, Gilsanz V, Lappe JM, Oberfield S, Shepherd JA, Frederick MM, Huang X, Lu M, Mahboubi S, Hangartner T, Winer KK (2011) Revised reference curves for bone mineral content and areal bone mineral density according to age and sex for black and non-black children: results of the bone mineral density in childhood study. J Clin Endocrinol Metab 96(10): 3160-3169

16. Jurimae $\mathbf{J}$ (2010) Interpretation and application of bone turnover markers in children and adolescents. Curr Opin Pediatr 22(4): 494-500

17. Glorieux FH, Pettifor JM, J ü ppner H (2011) Pediatric bone: biology and diseases, 2nd edn. Academic Press, Cambridge

18. Rauchenzauner M, Schmid A, Heinz-Erian P, Kapelari K, Falkensammer G, Griesmacher A, Finkenstedt G, Högler W (2007) Sex- and age-specific reference curves for serum markers of bone turnover in healthy children from 2 months to 18 years. J Clin Endocrinol Metab 92(2):443-449

19. Mora S, Puzzovio M, Giacomet V, Fabiano V, Maruca K, Capelli S, Nannini P, Lombardi G, Zuccotti GV (2015) Sclerostin and DKK1: two important regulators of bone metabolism in HIV-infected youths. Endocrine 49(3):783-790

20. Sudjaritruk T, Bunupuradah T, Aurpibul L, Kosalaraksa P, Kurniati N, Prasitsuebsai W, Sophonphan J, Sohn AH, Ananworanich J, Puthanakit T, the Bone-D Study Group (2017) Adverse bone health and abnormal bone turnover among perinatally HIV-infected Asian adolescents with virological suppression. HIV Med 18(4):235-244

21. Eckard AR, O'Riordan MA, Rosebush JC, Lee ST, Habib JG, Ruff $\mathrm{JH}$ et al (2017) Vitamin D supplementation decreases immune activation and exhaustion in HIV-1-infected youth. Antivir Ther. https://doi.org/10.3851/IMP3199

22. Mora S, Zamproni I, Cafarelli L, Giacomet V, Erba P, Zuccotti G, Viganò A (2007) Alterations in circulating osteoimmune factors may be responsible for high bone resorption rate in HIV-infected children and adolescents. AIDS 21(9):1129-1135

23. Bi X, Ishizaki A, Nguyen LV, Matsuda K, Pham HV, Phan CT, Ogata K, Giang T, Phung T, Nguyen T, Tokoro M, Pham A, Khu D, Ichimura H (2016) Impact of HIV infection and anti-retroviral therapy on the immune profile of and microbial translocation in HIV-infected children in Vietnam. Int J Mol Sci 17(8)

24. Ruan A, Tobin NH, Mulligan K, Rollie A, Li F, Sleasman J, Aldrovandi GM (2016) Brief report: macrophage activation in HIV-infected adolescent males contributes to differential bone loss by sex: adolescent trials network study 021. J Acquir Immune Defic Syndr 72(4):372-375

25. Sandler NG, Wand H, Roque A, Law M, Nason MC, Nixon DE, Pedersen C, Ruxrungtham K, Lewin SR, Emery S, Neaton JD, Brenchley JM, Deeks SG, Sereti I, Douek DC, INSIGHT SMART Study Group (2011) Plasma levels of soluble CD14 independently predict mortality in HIV infection. J Infect Dis 203(6): 780-790

26. Tenorio AR, Zheng Y, Bosch RJ, Krishnan S, Rodriguez B, Hunt PW, Plants J, Seth A, Wilson CC, Deeks SG, Lederman MM, Landay AL (2014) Soluble markers of inflammation and coagulation but not T-cell activation predict non-AIDS-defining morbid events during suppressive antiretroviral treatment. J Infect Dis 210(8):1248-1259 
27. Yin MT, Brown TT (2016) HIV and bone complications: understudied populations and new management strategies. Curr HIV/AIDS Rep 13(6):349-358

28. Chen L, Jarujaron S, Wu X, Sun L, Zha W, Liang G, Wang X, Gurley EC, Studer EJ, Hylemon PB, Pandak WM Jr, Zhang L, Wang G, Li X, Dent P, Zhou H (2009) HIV protease inhibitor lopinavir-induced TNF-alpha and IL-6 expression is coupled to the unfolded protein response and ERK signaling pathways in macrophages. Biochem Pharmacol 78(1):70-77

29. Ofotokun I, Titanji K, Vikulina T, Roser-Page S, Yamaguchi M, Zayzafoon M, Williams IR, Weitzmann MN (2015) Role of T-cell reconstitution in HIV-1 antiretroviral therapy-induced bone loss. Nat Commun 6:8282

30. Ofotokun I, Titanji K, Vunnava A, Roser-Page S, Vikulina T, Villinger F, Rogers K, Sheth AN, Lahiri CD, Lennox JL, Weitzmann MN (2016) Antiretroviral therapy induces a rapid increase in bone resorption that is positively associated with the magnitude of immune reconstitution in HIV infection. AIDS 30(3): 405-414

31. Sack U, Burkhardt U, Borte M, Schadlich H, Berg K, Emmrich F (1998) Age-dependent levels of select immunological mediators in sera of healthy children. Clin Diagn Lab Immunol 5(1):28-32 